\title{
Prenatal Diagnosis of Abnormal Sternum Development and Dilated Aortic Root in a Fetus with a Novel 204 kb Microdeletion of the TGFRB2 Gene
}

\author{
Rebecca A. Feldman'1, Justin S. Brandt ${ }^{2}$, Beverly Coleman ${ }^{3}$, Michael T. Mennuti ${ }^{1}$ \\ ${ }^{1}$ Maternal and Child Health Research Program, Department of Obstetrics and Gynecology, Center for Research on Reproduction and \\ Women's Health, University of Pennsylvania, Perelman School of Medicine, Philadelphia, USA \\ ${ }^{2}$ Rutgers-Robert Wood Johnson Medical School, Department of OBGYN, Maternal Fetal Medicine, New Brunswick, USA \\ ${ }^{3}$ Department of Radiology, Hospital of the University of Pennsylvania, Philadelphia, USA \\ Email: rebecca.feldman@uphs.upenn.edu
}

How to cite this paper: Feldman, R.A., Brandt, J.S., Coleman, B. and Mennuti, M.T. (2016) Prenatal Diagnosis of Abnormal Sternum Development and Dilated Aortic Root in a Fetus with a Novel $204 \mathrm{~kb}$ Microdeletion of the TGFRB2 Gene. Open Journai of Obstetrics and Gynecology, 6, 601-605. http://dx.doi.org/10.4236/ojog.2016.610075

Received: August 13, 2016

Accepted: September 10, 2016

Published: September 13, 2016

Copyright $\odot 2016$ by authors and Scientific Research Publishing Inc. This work is licensed under the Creative Commons Attribution International License (CC BY 4.0).

http://creativecommons.org/licenses/by/4.0/

\begin{abstract}
The Loeys-Dietz syndrome (LDS) is a connective tissue disorder that is associated with vascular abnormalities, including aggressive aortic aneurysms, as well as skeletal and craniofacial malformations. The molecular mechanism of this syndrome remains to be fully elucidated. In this case, we describe a 29 -year-old woman, gravida 2 para 1 , who was referred for consultation after urinary tract malformations were observed during her mid-gestation anatomic survey. Following referral to our unit, ultrasound examination of the 21-week fetus was repeated. The fetus was observed to have a dilated aortic root and a poorly ossified sternum with mild pectus deformity. After elective termination, single nucleotide polymorphism microarray testing identified a novel $204 \mathrm{~kb}$ microdeletion involving the short arm of chromosome 3 . The deleted genetic material included 4 exons of the TGFBR2 gene. Although the phenotype of LDS may be caused by haploinsufficiency of the TGFBR1 or TGFBR2 gene, our experience suggests a more complex picture of LDS. The study of such cases might further elucidate its pathogenesis.
\end{abstract}

\section{Keywords}

Loeys-Dietz Syndrome, Connective Tissue Disorders, Dilated Aortic Root, TGFBR1, TGFBR2

\section{Introduction}

The Loeys-Dietz syndrome (LDS) is a rare connective tissue disorder described only in 
case series [1] [2]. It is associated with vascular abnormalities, including aggressive aortic aneurysms, skeletal malformations, including pectus excavatum and scoliosis, and craniofacial malformations, such as bifid uvula. LDS is generally suspected in children who have clinical stigmata or based on a significant family history. There are two types of LDS: type I, which encompasses $75 \%$ of cases, is associated with vascular, skeletal, cutaneous, and craniofacial findings; type II is associated with similar malformations, although craniofacial abnormalities are not seen. The molecular mechanism of this syndrome is complex and remains to be fully elucidated [3]. Two major genes, encoding the transforming growth factor $\beta$ receptors 1 and 2, TGFBR1 and TGFBR2, were originally associated with LDS. Most recently, mutations in the gene encoding SMAD3 and TGFB2 have been associated with LDS-like presentations. Mutations are primarily missense and located in the $\mathrm{C}$ terminal of the serine/threonine kinase domain [1]. While specific diagnostic criteria have not been established, testing for these genetic mutations is indicated when specific malformations are identified.

The mean age of death in LDS patients is 26.1 years [1]. The major sources of morbidity and mortality in LDS are attributed to aortic dissection and rupture, mitral valve prolapse, and enlargement of the proximal pulmonary artery [1]. Histologically, fragmentation of elastic fibers, loss of elastin content, and accumulation of amorphous matrix components occur in the aorta [1]. Upon postnatal diagnosis, clinical evaluation includes echocardiogram, full body MRI or CT to assess for aneurysms, radiographs for skeletal abnormalities, and craniofacial and ophthalmologic physical examinations [4]. For the cardiovascular manifestations, beta-adrenergic medications are used to control hemodynamic parameters. Early surgical interventions of aneurysms and the ascending aorta can be life-saving [5]. Surgical correction may also be necessary for cervical spine instability, clubfeet, and other associated skeletal issues.

The prenatal diagnosis of LDS due to a de novo mutation of TGFBR2 in a 19-week fetus with aortic aneurysm was reported shortly after the syndrome was described [6]. To our knowledge, the only additional case of prenatal diagnosis involved the finding of a complex congenital heart defect (double outlet right ventricle with interrupted aortic arch) associated with a mutation in TGFBR1 [7]. Our recent experience with the early second trimester detection of an additional fetus with features of LDS, including aortic findings, and deletion of TGFBR2 (rather than a mutation), prompted this report.

\section{Case Report}

A 29-year-old woman, gravida 2 para 1, was referred after urinary tract abnormalities were observed during her mid-gestation anatomic survey. Following referral to our unit, ultrasound examination of the 21 week fetus was repeated. The fetus was observed to have a dilated aortic root (Figure 1) and a poorly ossified sternum with mild pectus deformity. In addition, there was a thick walled urinary bladder, small echogenic kidneys, and bilateral megaureters. A hyper flexed left lower extremity was noted. Fetal echocardiography revealed mild to moderate aortic root dilation of $0.62 \mathrm{~cm}$; a normal aortic root at this gestational age would measure between $0.25 \mathrm{~cm}$ and $0.45 \mathrm{~cm}$ [8]. The 


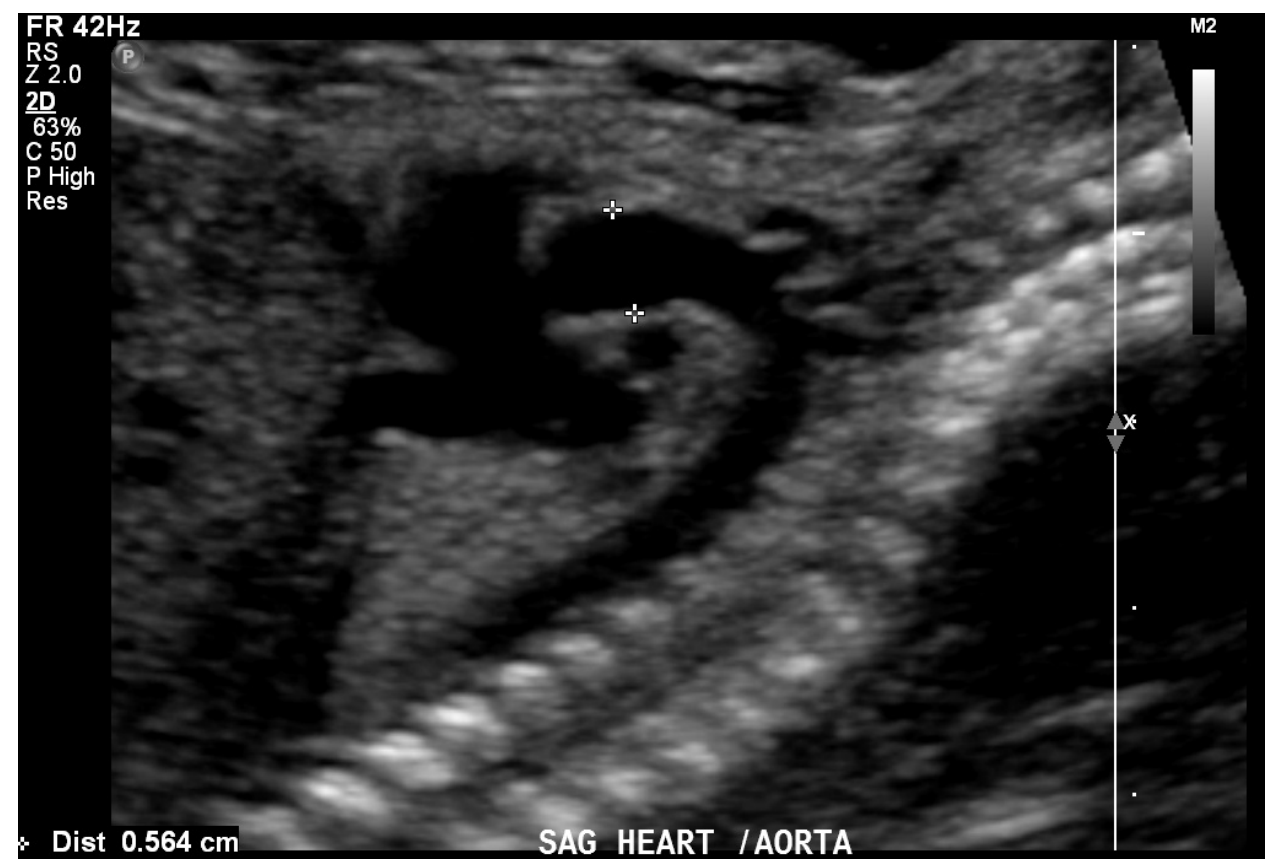

Figure 1. Prenatal ultrasound at 19 weeks revealed mild to moderate aortic root dilation of 0.62 $\mathrm{cm}$. A normal aortic root at this gestational age would measure between $0.25 \mathrm{~cm}$ and $0.45 \mathrm{~cm}$ [8].

fetal brain appeared normal on magnetic resonance imaging (MRI). The pectus deformity was also confirmed on MRI.

The patient was counseled about the findings and was offered amniocentesis for prenatal diagnosis. She declined invasive testing, instead electing pregnancy termination. She had an uncomplicated dilation and evacuation at 21.5 weeks. Fetal tissues were not examined for anatomic evaluation, but were sent for cytogenetic testing. The karyotype results were normal (46, XY). Residual cells from tissue culture were submitted for microarray testing. Single nucleotide polymorphism microarray testing identified a novel $204 \mathrm{~kb}$ microdeletion involving the short arm of chromosome 3 (arr [hg 19] 3 p 24.1 p $23(30,707,262-30,911,149) \times 1)$ indicating monosomy for this region. Deleted genetic material included 4 exons of the TGFBR2 gene and 14 exons of the GADL1 gene.

Neither the patient nor her husband had clinical histories suggestive of LDS, and their family histories were negative for suspected cases. Genetic counseling and parental testing were strongly recommended, but neither was accepted at the time of this report.

\section{Discussion}

The molecular mechanism for LDS is not entirely clear. The disorder, which is associated with high transforming growth factor (TGF- $\beta$ ) signaling in affected tissues, is most often due to heterozygous mutations in genes responsible for positive effectors of TGF- $\beta$ (e.g. TGFBR1, TGFBR2, and SMAD3). More than 70 mutations of the TGFBR2 gene have been reported in patients with LDS, of which the majority are missense 
mutations. The role of the increased TGF- $\beta$ signaling in the development and progression of features of the syndrome, particularly aortic aneurysms, is not understood. Previously reported cases of children with TGFBR1 and TGFBR2 deletions have not had aortic findings on clinical evaluation, although longer follow-up is not available [9] [10]. Most recently, loss of function mutations in theTGFBR2 gene have been reported to cause syndromic presentation of thoracic aortic aneurysm with features that overlap with LDS [11]. Thus, the complex pathogenesis of this hereditary connective tissue disorder remains uncertain.

Our case is noteworthy in that disruption of the TGFBR2 gene was identified in a fetus with multiple malformations. We believe that the deletion of four exons of the TGFBR2 gene together with a dilated aortic root and the sternal abnormality are consistent with a diagnosis of LDS. To address whether the identified deletion was a benign copy number variant, several databases collectively containing over 17,000 normal patients were screened and no individuals found with similar losses disrupting TGFBR2 [10]. The hyperflexion of the left foot might also be consistent with the syndrome, but we are unable to relate the urinary tract findings to this diagnosis as this has not been seen in association with TGFBR mutations up to this point. The other gene disrupted by the deletion, GADL1, encodes a cytosolic enzyme called glutamate decarboxylaselike protein. This mutation has yet to be associated with a known disease or phenotype. Cytosolic enzymes are not typically dosage dependent [12], and thus we suspect that a microdeletion involving the GADL1 gene is unlikely to be responsible for the ultrasound findings in the fetus of our patient.

\section{Conclusion}

In the other reported cases of microdeletions involving the TGFBR1 and TGFBR2 genes, aortic involvement was absent [7] [8]. Campbell et al. states that haploinsufficiency causes a phenotype that is distinct from LDS, but he concludes that longer follow-up is warranted. In contrast, our experience with a novel microdeletion involving only 4 exons of TGFBR2 gene (which are included in Campbell's microdeletion) suggests a more complicated picture. We believe that the study of similar cases might provide understanding of the basis for the discordance between the findings in these cases and contribute to further elucidating the pathogenesis of LDS syndrome. We also believe that calling attention to our experience and the previously reported prenatal diagnoses may lead to including LDS in the differential diagnosis of dilated aortic root or related findings during mid-gestation ultrasounds. Evaluation of such cases by testing for deletions and sequencing the putative genes might provide clinically important information for these patients.

\section{References}

[1] Loeys, B.L., Schwarze, U., Holm, T., et al. (2006) Aneurysm Syndromes Caused by Mutations in the TGF-Beta Receptor. The New England Journal of Medicine, 355, 788-798. http://dx.doi.org/10.1056/NEJMoa055695

[2] Loeys, B.L., Chen, J., Neptune, E.R., et al. (2005) A Syndrome of Altered Cardiovascular, 
Craniofacial, Neurocognitive and Skeletal Development Caused by Mutations in TGFBR1 or TGFBR2. Nature Genetics, 37, 275-281. http://dx.doi.org/10.1038/ng1511

[3] Lindsay, M.E. and Dietz, H.C. (2011) Lessons on the Pathogenesis of Aneurysm from Heritable Conditions. Nature, 473, 308-316. http://dx.doi.org/10.1038/nature10145

[4] Loeys, B.L. and Dietz, H.C. (2008) Loeys-Dietz Syndrome. Gene Reviews, Seattle.

[5] Beaulieu, R.J., Lue, J., Ehlert, B.A., et al. (2016) Surgical Management of Peripheral Vascular Manifestations of Loeys-Dietz Syndrome. Annals of Vascular Surgery.

http://dx.doi.org/10.1016/j.avsg.2016.06.007

[6] Viassolo, V., Lituania, M., Marasini, M., Dietz, H., et al. (2006) Fetal Aortic Root Dilation: A Prenatal Feature of Loeys-Dietz Syndrome. Prenatal Diagnosis, 26, 1081-1083. http://dx.doi.org/10.1002/pd.1565

[7] Kawazsu, Y., Inamura, N., Kayatani, F., Okamoto, N., et al. (2012) Prenatal Complex Congenital Heart Disease with Loeys-Dietz Syndrome. Cardiology in the Young, 22, 116-119. http://dx.doi.org/10.1017/S1047951111001028

[8] Drose, J. (2010) Fetal Echocardiography. 2nd Edition, Saunders, St. Louis.

[9] Redon, R., Baujat, G., Sanlaville, D., et al. (2006) Interstitial 9q22.3 Microdeletion: Clinical and Molecular Characterization of a Newly Recognized Overgrowth Syndrome. European Journal of Human Genetics, 14, 759-767. http://dx.doi.org/10.1038/sj.ejhg.5201613

[10] Campbell, I.M., Kolodziejska, K.E., Quach, M., Wolf, V.L., et al. (2011) TGFBR2 Deletion in a 20-Month-Old Female with Developmental Delay and Microcephaly. American Journal of Medical Genetics Part A, 155, 1442-1447. http://dx.doi.org/10.1002/ajmg.a.34015

[11] Lindsay, M., Schepers, D., Bolar, N., Doyle, J., et al. (2012) Loss-of-Function Mutations in TGFB2 Cause a Syndromic Presentation of Thoracic Aortic Aneurysm. Nature Genetics, 44, 890-894. http://dx.doi.org/10.1038/ng.2349

[12] Phadnis, N. and Fry, J.D. (2005) Widespread Correlations between Dominance and Homozygous Effects of Mutations: Implications for Theories of Dominance. Genetics, 171, 385-392. http://dx.doi.org/10.1534/genetics.104.039016

\section{Submit or recommend next manuscript to SCIRP and we will provide best service for you:}

Accepting pre-submission inquiries through Email, Facebook, LinkedIn, Twitter, etc.

A wide selection of journals (inclusive of 9 subjects, more than 200 journals)

Providing 24-hour high-quality service

User-friendly online submission system

Fair and swift peer-review system

Efficient typesetting and proofreading procedure

Display of the result of downloads and visits, as well as the number of cited articles

Maximum dissemination of your research work

Submit your manuscript at: http://papersubmission.scirp.org/ 